\title{
Lifestyle risk factors for overweight in Japanese male college students
}

\author{
Masashi Goto ${ }^{1, *}$, Kohsuke Kiyohara ${ }^{2}$ and Takashi Kawamura ${ }^{1}$ \\ ${ }^{1}$ Kyoto University Health Service, Kyoto, Japan: ${ }^{2}$ Department of Preventive Services, Kyoto University School of \\ Public Health, Kyoto, Japan
}

Submitted 8 November 2008: Accepted 5 November 2009: First published online 22 December 2009

\begin{abstract}
Objective: To identify lifestyle and sociodemographic risk factors of overweight among male college students.

Design: A retrospective cohort study.

Setting: Annual health checkup in a single university in Japan.

Participants: Male students who underwent two successive health checkups from their third school year between 2000 and 2007 and whose BMI at baseline of this study was $22 \cdot 0 \mathrm{~kg} / \mathrm{m}^{2}$ or more $(n 4634)$.

Results: During the 1-year follow-up, 598 students (12.9\%) reached the study endpoint, i.e. more than a $5 \%$ increase in BMI. Independent risk factors for substantial BMI increase included infrequent exercise (OR $=1 \cdot 33$; $95 \%$ CI 1.11, 1.60), no or infrequent alcohol drinking $(\mathrm{OR}=1 \cdot 30 ; 95 \%$ CI $1 \cdot 08,1 \cdot 57)$, frequently skipping breakfast (OR $=1 \cdot 34 ; 95 \%$ CI $1 \cdot 12,1 \cdot 61$ ), preference for fatty food (OR $1 \cdot 36 ; 95 \%$ CI $1 \cdot 04,1 \cdot 78)$ and living alone $(\mathrm{OR}=1 \cdot 23 ; 95 \% \mathrm{CI} 0 \cdot 99,1 \cdot 52)$. Students were readily stratified according to risk for substantial BMI gain by counting the number of their risk factors. OR $(95 \% \mathrm{CI})$ for the risk between the no risk factor group and students with two, three, four and five risk factors were 1.61 (0.96, $2 \cdot 70), 2 \cdot 24(1 \cdot 34,3 \cdot 75), 2 \cdot 42(1 \cdot 39,4 \cdot 23)$ and $6 \cdot 22(2 \cdot 58,15 \cdot 0)$, respectively.

Conclusion: These data suggest that avoidance of certain risk factors in college life is associated with a decrease in incidence of overweight among male students.
\end{abstract}

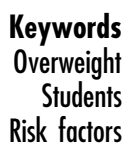

Overweight

Students

Risk factors
Obesity has become one of the most important public health problems in the world ${ }^{(1)}$. Difficulties of weight control for obese people indicate that prevention may be the best possible approach to struggle against this obesity epidemic; interventions should be taken before adult lifestyle patterns solidify such as high fat intake and sedentariness. An article on schoolchildren revealed that the attitude towards healthy lifestyle in their school days had a significant impact on their later life ${ }^{(2)}$. Thus far, however, lifestyle modification in younger generations has not been thoroughly discussed.

According to the white paper on college student health $^{(3,4)}$ issued every 5 years by the National University Council of Health Administration Facilities, the proportion of male overweight or obese students (BMI $\geq 25 \cdot 0 \mathrm{~kg} / \mathrm{m}^{2}$ ) increased from $9.8 \%$ in 2000 to $11.7 \%$ in 2005 in Japan. Furthermore, the prevalence of obesity increased at around age 23 years and thereafter, indicating that many students would graduate without acquiring a healthy lifestyle and begin to gain weight when employed because of the decrease in exercise and the exposure to many stressors in hardworking Japanese society. According to the annual report of the Japanese
Ministry of Education, Culture, Sports, Science and Technology, as many as $51.5 \%$ of the Japanese people matriculated to a university in $2005^{(5)}$. We, therefore, must discuss in more detail student lifestyle modification as a matter of higher education.

Because factors of obesity may vary among and within societies exposed to different environments ${ }^{(6)}$ and little is known about the factors that contribute to the worldwide obesity epidemic, it is meaningful to evaluate the factors that determine the obesity process in different regions and different cultures. BMI in childhood, parents' weights and 'Western' dietary pattern, characterised by high intakes of meats, fats and oils, seasonings, processed meats and eggs, have been suggested to have an association with overweight or obesity among Japanese college students ${ }^{(7,8)}$. However, all these studies were conducted in a cross-sectional manner, and the causal relationship between lifestyle of Japanese college students and incidence of overweight has not been examined by a cohort design.

Thus, the objective of the current study is to identify lifestyle and sociodemographic risk factors for becoming overweight among male college students and to construct 
a self-administered tool to stratify students according to the risk of overweight based on the cohort data collected at the annual health checkups.

\section{Methods}

We carry out a health checkup for the students of Kyoto University every spring according to the School Health Law (http://www.houko.com/00/01/S33/056.HTM). We analysed the data from anthropometry and the selfadministered questionnaire about lifestyle, both of which were routinely collected in the annual health checkups between 2000 and 2007. The data included sex, age, major, nationality, height, weight, family history of some specific pathologies (diabetes mellitus, hypertension and dyslipidaemia), past medical history, current illness and residential environment (living alone or with family). Information on dietary habits such as frequencies of eating out for dinner and skipping breakfast, dietary preferences, exercise frequency, as well as sleeping, smoking and drinking habits were also included. The lifestyle questionnaire was delivered to individual students in advance and collected at the health checkup site. Weight and height were measured while wearing light clothes, but with their shoes off, subtracting the presumed weight of clothes, and determined to the nearest $0 \cdot 1 \mathrm{~kg}$ and $0 \cdot 1 \mathrm{~cm}$, respectively. BMI was calculated as weight $(\mathrm{kg})$ divided by the square of height $(\mathrm{m})$.

Male students who underwent the health checkups in both their third and fourth years and whose BMI in the third year was $22.0 \mathrm{~kg} / \mathrm{m}^{2}$ or more were included in the analyses because the increase in BMI should not be a health problem for the students whose baseline BMI was less than $22 \cdot 0 \mathrm{~kg} / \mathrm{m}^{2}$. The study endpoint was more than a $5 \%$ increase in BMI over the former year: corresponding weight gain of $3.2 \mathrm{~kg}$ or more in a student with $170 \mathrm{~cm}$ in height and $64 \mathrm{~kg}$ in weight (BMI, nearly equal $22 \cdot 0 \mathrm{~kg} /$ $\mathrm{m}^{2}$ ). Because the present study was merely a retrospective analysis of routinely collected data in the legislated health checkup, informed consent from participants was not required for the study ${ }^{(9)}$.

\section{Statistical analysis}

OR of potential predictive factors for BMI increase were estimated using the logistic regression model. The independent effect of each variable was assessed by multivariable analysis. Here, frequencies of skipping breakfast, eating out and exercise were dichotomised by twice a week or more or not. Even though the drinking habit was also dichotomised by no or infrequent drinking or not for the construction of the prediction model, it was classified in more detail to closely assess the relationship between alcohol consumption and BMI gain: non- or infrequent, sometimes (several times per week or per month), daily (five times per week or more, less than $633 \mathrm{ml}$ of beer per day), and daily heavy (five times per week or more, $633 \mathrm{ml}$ of beer per day or more) drinkers. Height and weight were not included in the multivariable analysis because of their close relation with BMI. The number of significant predictors that the individual students possess was taken to be a score to estimate the risk of a substantial increase in BMI.

To clarify the utility of this prediction score, the actual proportion of students with an increase in BMI of more than $5 \%$ among those with the same score was calculated. The OR for the risk with the 95\% CI in students with each risk score compared to those without any risk factors were also calculated. The area under the receiveroperating characteristic (ROC) curve for the risk of a substantial increase in BMI was estimated by the nonparametric method.

The prediction score was applied to 100 bootstrap samples of the same size as the original data, and the $95 \%$ CI of the OR between the no risk factor group and other risk groups were estimated to validate the discriminant ability of the model ${ }^{(10)}$.

To assess how or whether in fact the prediction score related to the incidence of overweight, students with a baseline BMI of less than $24.0 \mathrm{~kg} / \mathrm{m}^{2}$ were stratified by the individual risk score. The incidence rate of overweight, a BMI of more than $25 \cdot 0 \mathrm{~kg} / \mathrm{m}^{2}$ in the fourth year, was then calculated.

Analyses were computed using Stata 10.1 software (Stata Corporation, College Station, TX, USA, 2009). All tests of significance were two-tailed, and values of $P<0.05$ were considered statistically significant.

\section{Results}

Among 14129 male students who underwent the health checkups in both their third and fourth years between 2000 and 2007 and their lifestyle data were available, 4634 students whose BMI in the third year was $22 \cdot 0 \mathrm{~kg} / \mathrm{m}^{2}$ or more were included in the current analysis. The analysis sample was on average $21 \cdot 5$ (SD 1.9) years of age and $24 \cdot 2$ (sD $2 \cdot 3) \mathrm{kg} / \mathrm{m}^{2}$ of BMI, and 1080 students $(23 \cdot 3 \%)$ had a BMI of more than $25.0 \mathrm{~kg} / \mathrm{m}^{2}$ in the third year. In the next year, 598 students $(12.9 \%)$ reached the endpoint, an increase in BMI of more than $5 \%$.

Table 1 summarises the demographic, anthropometric and lifestyle characteristics of the study subjects and their association with a $5 \%$ increase in BMI by univariable analysis. Living alone, sedentariness, no or infrequent alcohol drinking, frequently skipping breakfast and preference for fatty food were associated with the risk of BMI increase.

In the multivariable analysis, four of five variables significant in the univariable analysis were also independent predictors of weight gain, and another, living alone, had a marginally significant association with the risk (Table 2).

In Table 3, we show the proportion of students with an increase in BMI of more than 5\% among each risk score 
Table 1 Demographic, anthropometric and lifestyle characteristics of students and their association with a $5 \%$ increase in BMI (univariable analysis)

\begin{tabular}{|c|c|c|c|c|c|c|c|}
\hline & \multicolumn{4}{|c|}{ BMI gain $\geq 5 \%$} & \multirow[b]{3}{*}{ OR } & \multirow[b]{3}{*}{$95 \% \mathrm{Cl}$} & \multirow[b]{3}{*}{$P$ value } \\
\hline & \multicolumn{2}{|c|}{ Yes $(n 598)$} & \multicolumn{2}{|c|}{ No $(n$ 4036) } & & & \\
\hline & Mean or $n$ & SD or $\%$ & Mean or $n$ & SD or $\%$ & & & \\
\hline Age (years) & $21 \cdot 5$ & $1 \cdot 3$ & $21 \cdot 6$ & $1 \cdot 9$ & 0.97 & $0.92,1.03$ & 0.33 \\
\hline \multicolumn{8}{|l|}{ Nationality } \\
\hline Japan & 584 & $12 \cdot 8$ & 3978 & $87 \cdot 2$ & - & & \\
\hline Other countries & 14 & $19 \cdot 4$ & 58 & $80 \cdot \overline{6}$ & $1 \cdot 64$ & $0.91,2.97$ & 0.099 \\
\hline \multicolumn{8}{|l|}{ Major } \\
\hline Sciences & 370 & $12 \cdot 5$ & 2598 & $87 \cdot 5$ & - & & \\
\hline Arts & 228 & $13 \cdot 7$ & 1438 & $86 \cdot 3$ & $1 \cdot 11$ & $0.93,1.33$ & $0 \cdot 24$ \\
\hline Height (cm) & $172 \cdot 0$ & $6 \cdot 2$ & $172 \cdot 1$ & $5 \cdot 8$ & $1 \cdot 00$ & $0.99,1.00$ & 0.89 \\
\hline Weight (kg) & $72 \cdot 1$ & $9 \cdot 1$ & $71 \cdot 6$ & $8 \cdot 5$ & $1 \cdot 00$ & $0.99,1.00$ & $0 \cdot 15$ \\
\hline BMI $\left(\mathrm{kg} / \mathrm{m}^{2}\right)$ & $24 \cdot 3$ & $2 \cdot 4$ & $24 \cdot 1$ & $2 \cdot 3$ & 1.03 & $0.99,1.07$ & $0 \cdot 062$ \\
\hline \multicolumn{8}{|l|}{ Current illness } \\
\hline Absent & 561 & $13 \cdot 1$ & 3708 & $86 \cdot 9$ & - & & \\
\hline Present & 37 & $10 \cdot 1$ & 328 & 89.9 & $0 \cdot 75$ & $0.52,1 \cdot 06$ & $0 \cdot 10$ \\
\hline \multicolumn{8}{|l|}{ Past medical problem } \\
\hline Absent & 575 & $13 \cdot 1$ & 3820 & $86 \cdot 9$ & - & & \\
\hline Present & 23 & $9 \cdot 6$ & 216 & $90 \cdot 4$ & $0 \cdot 71$ & $0 \cdot 46,1 \cdot 10$ & $0 \cdot 12$ \\
\hline \multicolumn{8}{|c|}{ Family history of diabetes mellitus } \\
\hline Absent & 566 & $12 \cdot 8$ & 3851 & $87 \cdot 2$ & - & & \\
\hline Present & 32 & $14 \cdot 8$ & 185 & $85 \cdot \overline{3}$ & $1 \cdot 18$ & $0.80,1.73$ & 0.41 \\
\hline Family history of dyslipidem & & & & & & & \\
\hline Absent & 586 & $12 \cdot 9$ & 3969 & $87 \cdot 1$ & - & & \\
\hline Present & 12 & $15 \cdot 2$ & 67 & $84 \cdot 8$ & $1 \cdot 21$ & $0 \cdot 65,2 \cdot 26$ & 0.54 \\
\hline Residence & & & & & & & \\
\hline Living with family & 133 & $11 \cdot 0$ & 1073 & $89 \cdot 0$ & - & & \\
\hline Living alone & 465 & $13 \cdot 6$ & 2963 & $86 \cdot 4$ & $1 \cdot 27$ & $1 \cdot 03,1.55$ & 0.024 \\
\hline Exercise & & & & & & & \\
\hline Twice a week or more & 211 & $10 \cdot 8$ & 1735 & $89 \cdot 2$ & - & & \\
\hline Once a week or less & 382 & $14 \cdot 4$ & 2268 & $85 \cdot 6$ & $1 \cdot 38$ & $1 \cdot 16,1 \cdot 66$ & $<0.001$ \\
\hline Sleeping hours & & & & & & & \\
\hline Less than $8 \mathrm{~h}$ & 550 & $12 \cdot 7$ & 3786 & $87 \cdot 3$ & - & & \\
\hline $8 \mathrm{~h}$ or more & 42 & $15 \cdot 4$ & 230 & $84 \cdot 6$ & $1 \cdot 26$ & $0 \cdot 89,1 \cdot 77$ & $0 \cdot 19$ \\
\hline Current smoking & & & & & & & \\
\hline No & 509 & $12 \cdot 6$ & 3521 & $87 \cdot 4$ & - & & \\
\hline Yes & 89 & $14 \cdot 7$ & 515 & $85 \cdot 3$ & $1 \cdot 20$ & $0.94,1.52$ & $0 \cdot 15$ \\
\hline Alcohol drinking & & & & & & & \\
\hline Every day/often & 395 & $12 \cdot 1$ & 2868 & $87 \cdot 9$ & - & & \\
\hline Never/seldom & 203 & $14 \cdot 8$ & 1168 & $85 \cdot 2$ & $1 \cdot 26$ & $1 \cdot 05,1.51$ & 0.012 \\
\hline Eating out for dinner & & & & & & & \\
\hline Once a week or less & 183 & $12 \cdot 7$ & 1261 & $87 \cdot 3$ & - & & \\
\hline Twice a week or more & 415 & $13 \cdot 0$ & 2775 & $87 \cdot 0$ & 1.03 & $0 \cdot 86,1 \cdot 24$ & $0 \cdot 75$ \\
\hline Skipping breakfast & & & & & & & \\
\hline Once a week or less & 274 & $11 \cdot 2$ & 2180 & $88 \cdot 8$ & - & & \\
\hline Twice a week or more & 324 & $14 \cdot \overline{9}$ & 1856 & $85 \cdot 1$ & $1 \cdot 39$ & $1 \cdot 17,1 \cdot 65$ & $<0.001$ \\
\hline Current dietary restriction fo & & & & & & & \\
\hline No & 586 & $12 \cdot 8$ & 3989 & $87 \cdot 2$ & - & & \\
\hline Yes & 12 & $20 \cdot 3$ & 47 & $79 \cdot 7$ & $1 \cdot 74$ & $0.92,3.30$ & 0.090 \\
\hline Dietary preferences & & & & & & & \\
\hline Distaste for meat & & & & & & & \\
\hline No & 591 & $12 \cdot 9$ & 4006 & $87 \cdot 1$ & - & & \\
\hline Yes & 7 & $18 \cdot 9$ & 30 & $81 \cdot 1$ & $1 \cdot 58$ & $0.69,3.62$ & $0 \cdot 28$ \\
\hline Distaste for fish & & & & & & & \\
\hline No & 584 & $12 \cdot 9$ & 3960 & $87 \cdot 2$ & - & & \\
\hline Yes & 14 & $15 \cdot 6$ & 76 & $84 \cdot 4$ & $1 \cdot 25$ & $0 \cdot 70,2 \cdot 22$ & 0.45 \\
\hline Distaste for vegetables & & & & & & & \\
\hline No & 578 & $12 \cdot 9$ & 3918 & $87 \cdot 1$ & - & & \\
\hline Yes & 20 & $14 \cdot 5$ & 118 & $85 \cdot 5$ & $1 \cdot 15$ & $0 \cdot 71,1 \cdot 86$ & 0.57 \\
\hline Preference for salty foods & & & & & & & \\
\hline No & 534 & $12 \cdot 8$ & 3652 & $87 \cdot 2$ & - & & \\
\hline Yes & 64 & $14 \cdot 3$ & 384 & $85 \cdot 7$ & $1 \cdot 14$ & $0.86,1.51$ & $0 \cdot 36$ \\
\hline Preference for fatty foods & & & & & & & \\
\hline No & 524 & $12 \cdot 5$ & 3662 & $87 \cdot 5$ & - & & \\
\hline Yes & 74 & $16 \cdot 5$ & 374 & $83 \cdot 5$ & $1 \cdot 38$ & $1 \cdot 06,1 \cdot 80$ & 0.017 \\
\hline Preference for sweets & & & & & & & \\
\hline No & 506 & $12 \cdot 8$ & 3447 & $87 \cdot 2$ & - & & \\
\hline Yes & 92 & $13 \cdot 5$ & 589 & $86 \cdot 5$ & 1.06 & $0.84,1 \cdot 35$ & $0 \cdot 61$ \\
\hline
\end{tabular}

Values are expressed as mean and SD or number and \%. Sample sizes may vary among presented variables because of missing data. 
group and the OR of the risk using those without risk factors as the reference group. If the students did not have any risk factors, the incidence rate of a substantial increase in BMI was $7 \cdot 8 \%$, whereas students with all five risk factors had a $34 \cdot 4 \%$ incidence. Compared to students without risk factors, the OR for a substantial increase in BMI in those with two, three, and five risk factors were $1 \cdot 6(95 \%$ CI $0 \cdot 96,2 \cdot 70), 2 \cdot 2(95 \%$ CI $1 \cdot 34,3 \cdot 75)$ and $6 \cdot 2$ (95\% CI $2 \cdot 58,15 \cdot 0)$, respectively. The area under the ROC curve of this prediction model was 0.577 (95\% CI 0.553, 0.600).

The bootstrap estimates of $95 \%$ CI of the OR for more than $5 \%$ of an increase in BMI between the no risk factor group and other risk groups were reasonably narrow for most of the risk groups (Table 3 ). The subgroup analysis including students with a BMI of less than $24.0 \mathrm{~kg} / \mathrm{m}^{2}$ ( $n$ 2868) showed a gradual increase in the incidence of overweight, BMI of more than $25.0 \mathrm{~kg} / \mathrm{m}^{2}$, by increasing the number of risk factors at baseline; incidence rates of overweight during the next year were 2/142 (1.4\%), 11/626 (1.8\%), 37/1003 (3.7\%), 53/822 (6.5\%), 11/230 $(4 \cdot 8 \%)$ and $4 / 20(20 \cdot 0 \%)$ among students with zero, one, two, three, four and five risk factors, respectively.

In the multivariable model including the more closely classified alcohol variable instead of just the dichotomised one, the adjusted OR of sometimes ( $n$ 3085), daily ( $n$ 91), and daily heavy ( $n$ 54) drinkers compared with non- or infrequent drinkers ( $n$ 1371) were 0.76 (95\% CI 0.63 , $0 \cdot 92), 0.82(95 \%$ CI $0.44,1.54)$ and 1.01 (95\% CI $0 \cdot 49$, $2 \cdot 12)$, respectively.

\section{Discussion}

On the basis of the data obtained in our annual health checkup for college students, we identified the predictive

Table 2 Predictors of substantial BMI increase by multivariable analysis

\begin{tabular}{lccc}
\hline & OR & $95 \% \mathrm{Cl}$ & $P$ value \\
\hline $\begin{array}{l}\text { Skipping breakfast, twice a } \\
\text { week or more }\end{array}$ & 1.34 & $1.12,1.61$ & 0.002 \\
Exercise, once a week or less & 1.33 & $1.11,1.60$ & 0.002 \\
No or infrequent alcohol drinking & 1.30 & $1.08,1.57$ & 0.005 \\
Preference for fatty food & 1.36 & $1.04,1.78$ & 0.024 \\
Living alone & 1.23 & $0.99,1.52$ & 0.063 \\
\hline
\end{tabular}

indicators for substantial BMI increase and developed a prediction score for stratifying the students by risk of weight gain during 1 year. Sedentariness, no/infrequent alcohol drinking, frequently skipping breakfast, preference for fatty food and living alone were independently related to BMI increase. The prediction score successfully classified students according to their BMI-increase risk.

As the differences between males and females in exposure and vulnerability to obesogenic environments and the consequences of child and adolescent obesity were suggested in a review article ${ }^{(11)}$, and the proportion of female students among students with a baseline BMI of more than $22 \cdot 0 \mathrm{~kg} / \mathrm{m}^{2}$ was small $(636 / 5270,12 \cdot 1 \%)$, we included only male students in the current analysis. Actually, there was a significant male excess in risk of the substantial BMI increase (OR $=2 \cdot 40 ; 95 \%$ CI $1 \cdot 70,3 \cdot 38)$ when analysing the data set including both genders.

No or infrequent alcohol drinking was independently associated with the risk of substantial BMI increase in the current analysis. Alcoholic beverages may not substitute for other foods, but are energy dense and added to the total daily energy intake ${ }^{(12)}$. In addition, fat oxidation might be inhibited by the antilipolytic properties of metabolites from alcohol degradation ${ }^{(13-15)}$. These features could potentially promote fat storage and hence increase the risk of developing obesity. Nevertheless, results from the earlier epidemiological studies for the association between alcohol intake and obesity are inconsistent as to the role of alcohol consumption in obesity development ${ }^{(16)}$. If the observed associations between drinking frequency and obesity actually represent causal associations, a possible biological mechanism is a difference in the induction of the microsomal ethanoloxidising system (MEOS) by drinking frequency. In daily alcohol consumers, a larger fraction of the alcohol energy might be disposed of due to the induction of $\operatorname{MEOS}^{(17,18)}$.

Because the current results can be misconstrued by students as an encouragement to engage in heavy drinking, they must be carefully presented to the general public. Heavy drinking would cause considerable health problems and the significant excess risk of substantial BMI increase among non- or infrequent drinkers was not found in comparison with daily heavy drinkers in the current subanalysis. It is not easy to restrict alcohol consumption to low-to-moderate levels. Therefore, university health-care providers who use these results for health

Table 3 The proportion of students with an increase in BMI of more than $5 \%$ among each risk group and the OR for the risk

\begin{tabular}{lcccc}
\hline $\begin{array}{l}\text { Number of } \\
\text { risk factors }\end{array}$ & $\begin{array}{c}\text { Proportion of students with more } \\
\text { than 5\% of the BMI increase (\%) }\end{array}$ & OR & $95 \% \mathrm{Cl}$ & $\begin{array}{c}95 \% \mathrm{Cl} \text { estimated by } \\
\text { the bootstrap method }\end{array}$ \\
\hline 0 & $17 / 219(7 \cdot 8)$ & - & - & - \\
1 & $93 / 996(9 \cdot 3)$ & $1 \cdot 22$ & $0 \cdot 71,2 \cdot 10$ & $0 \cdot 77,1 \cdot 93$ \\
2 & $192 / 1612(11 \cdot 9)$ & $1 \cdot 61$ & $0 \cdot 96,2 \cdot 70$ & $1 \cdot 01,2 \cdot 57$ \\
3 & $209 / 1318(15 \cdot 9)$ & $2 \cdot 24$ & $1 \cdot 34,3 \cdot 75$ & $1 \cdot 42,3 \cdot 54$ \\
4 & $71 / 419(17 \cdot 0)$ & $2 \cdot 42$ & $1 \cdot 39,4 \cdot 23$ & $1 \cdot 46,4 \cdot 03$ \\
5 & $11 / 32(34 \cdot 4)$ & $6 \cdot 22$ & $2 \cdot 58,15 \cdot 0$ & $2 \cdot 38,16 \cdot 3$ \\
\hline
\end{tabular}


promotion should make an appeal to students not to indulge in alcohol.

This prediction model is so simple that students can easily grasp their own risk for weight gain during the following year by counting the number of risk factors they have, which would be a cue to action towards establishing a healthy lifestyle. For example, a student with three risk factors can readily become aware that he is more than twice more likely to gain substantial weight $(\mathrm{OR}=2 \cdot 2)$ than the students without any risk factors. In addition, implementation of this prediction model in mass screening would promote social norms encouraging healthy behaviours. To be specific, we intend to post the results or give a leaflet to students at a health checkup site. Perhaps, health-care providers in the university health service might use this score to concentrate their effort on the high-risk students.

Because this is a retrospective analysis of routinely collected data, we could not obtain sufficient information about already known environmental and genetic risk factors of obesity in youths. For example, the amount of time spent in watching television and using electronic games is directly related to the prevalence of obesity in children and adolescents ${ }^{(19-24)}$. Parents' BMI was the best predictor of overweight according to the case-control study among Brazilian adolescents ${ }^{(25)}$. Furthermore, two studies suggested that a variant in the FTO gene on chromosome 16 would affect the risk of obesity in the general population ${ }^{(26,27)}$. Some specific eating patterns such as restrained, disinhibited and emotional eating were also indicated to be strong predictors of future weight gain ${ }^{(28-31)}$. The lack of information on these factors might cause the relatively low accuracy of the current predictive model (the area under the ROC curve, 0.58).

Some other potential limitations of the current analysis must be acknowledged. First, most of the candidate predictors were solely based on the students' self-report, and no objective measures were used except for height and weight. Indeed, the bias attributable to self-report may have occurred, but self-reporting has been widely used in behavioural sciences with some validity shown in comparative studies using physiological markers. It is also acceptable in terms of feasibility ${ }^{(32)}$. Second, body composition of the study subjects was not known from the obtained data. Therefore, we could not identify the components of weight gain, muscle or fat. Third, the current prediction model was developed in a single university in Japan, and the applicability of the results to other colleges and races was not verified. Even though the prevalence of overweight or obesity was lower in the population of the current analysis (1080/14129 (7.6\%)) than in Japanese male college students as a whole $(9 \cdot 8 \%$ and $11.7 \%$ in 2000 and 2005, respectively) $)^{(3,4)}$, lifestyles of the Kyoto University students did not much differ from those of other university students ${ }^{(3)}$. Thus, the current prediction model can be reasonably useful for Japanese university students. Additionally, because factors which determine the process of obesity may be closely related to the exposed environments ${ }^{(6)}$, identification of the obesogenic factors in different regions in the world is meaningful.

In summary, the present study revealed that infrequent exercise, no or infrequent alcohol drinking, frequently skipping breakfast, preference for fatty food and living alone were independent risk factors for substantial BMI increase in Japanese male college students. These risk factors can predict future obesity rather well and are readily applicable for mass screening. A clear knowledge of such factors would thus help motivate students to improve their lifestyle health behaviours.

\section{Acknowledgements}

Each author has contributed significantly to this work. To be specific, M.G. conceived of the study, analysed and interpreted data and drafted the manuscript. K.K. assisted with the statistical analysis and T.K. critically reviewed the manuscript. All the authors have no financial support and potential conflicts of interest to disclose.

\section{References}

1. Kellner K \& Helmuth L (2003) Obesity - what is to be done? Science 299, 845.

2. Cohen RY, Brownell KD \& Felix MR (1990) Age and sex differences in health habits and beliefs of schoolchildren. Health Psychol 9, 208-224.

3. Japanese National University Council of Health Addministration Facilities (2005) White Paper on College Student Health 2005. http://hotai1.htc.nagoya-u.ac.jp/ kondo/ hakusho/hakusho2005

4. Japanese National University Council of Health Addministration Facilities (2000) White Paper on College Student Health 2000. http://hotai1.htc.nagoya-u.ac.jp/ kondo/ hakusho/hakusho2000

5. Annual Report of the Japanese Ministry of Education, Culture, Sports, Science, and Technology (2005) http:// www.mext.go.jp/b_menu/toukei/001/04073001/001.htm

6. Parsons TJ, Power C, Logan S et al. (1999) Childhood predictors of adult obesity: a systematic review. Int J Obes Relat Metab Disord 23, S1-S107.

7. Okubo H, Sasaki S, Murakami K et al., Freshmen in Dietetic Courses Study II group (2008) Three major dietary patterns are all independently related to the risk of obesity among 3760 Japanese women aged $18-20$ years. Int J Obes (Lond) 32, 541-549.

8. Kubo T, Furujo M, Ueda Y et al. (2008) Predicting obesity in early adulthood in Japanese women. I Paediatr Child Health 44, 33-37.

9. Japanese Ministries of Education, Culture, Sports, Science and Technology and Health, Labour and Welfare (2002, revised in 2007) Ethical Guideline for Epidemiological Research. http://www.lifescience.mext.go.jp/bioethics/ ekigaku.html

10. Efron B \& Tibshirani $\mathrm{R}$ (1993) An Introduction to the Bootstrap. Monographs on Statistics and Applied Probability. New York: Chapman \& Hall.

11. Sweeting HN (2008) Gendered dimensions of obesity in childhood and adolescence. Nutr J 7, 1. 
12. Colditz GA, Giovannucci E, Rimm EB et al. (1991) Alcohol intake in relation to diet and obesity in women and men. Am J Clin Nutr 54, 49-55.

13. Suter PM, Schutz Y \& Jequier E (1992) The effect of ethanol on fat storage in healthy subjects. $N$ Engl J Med 326, 983-987.

14. Sonko BJ, Prentice AM, Murgatroyd PR et al. (1994) Effect of alcohol on postmeal fat storage. Am J Clin Nutr 59, 619-625.

15. Murgatroyd PR, Van De Ven ML, Goldberg GR et al. (1996) Alcohol and the regulation of energy balance: overnight effects on diet-induced thermogenesis and fuel storage. Br J Nutr 75, 33-45.

16. Suter PM (2005) Is alcohol consumption a risk factor for weight gain and obesity? Crit Rev Clin Lab Sci 42, 197-227.

17. Levine JA, Harris MM \& Morgan MY (2000) Energy expenditure in chronic alcohol abuse. Eur J Clin Invest 30, 779-786.

18. Suter PM (2000) The paradox of the alcohol-paradox another step towards the resolution of the 'alcohol energy wastage' controversy. Eur J Clin Invest 30, 749-750.

19. Dietz WH Jr \& Gortmaker SL (1985) Do we fatten our children at the television set? Obesity and television viewing in children and adolescents. Pediatrics 75, 807-812.

20. Gortmaker SL, Must A, Sobol AM et al. (1996) Television viewing as a cause of increasing obesity among children in the United States, 1986-1990. Arch Pediatr Adolesc Med 150, 356-362.

21. Kaur H, Choi WS, Mayo MS et al. (2003) Duration of television watching is associated with increased body mass index. J Pediatr 143, 506-511.

22. Berkey CS, Rockett HR, Gillman MW et al. (2003) One-year changes in activity and in inactivity among 10- to 15-yearold boys and girls: relationship to change in body mass index. Pediatrics 111, 836-843.
23. Stettler N, Signer TM \& Suter PM (2004) Electronic games and environmental factors associated with childhood obesity in Switzerland. Obes Res 12, 896-903.

24. Kautiainen S, Koivusilta L, Lintonen T et al. (2005) Use of information and communication technology and prevalence of overweight and obesity among adolescents. Int $J$ Obes (Lond) 29, 925-933.

25. Neutzling MB, Taddei JA \& Gigante DP (2003) Risk factors of obesity among Brazilian adolescents: a case-control study. Public Health Nutr 6, 743-749.

26. Frayling TM, Timpson NJ \& Weedon MN (2007) A common variant in the FTO gene is associated with body mass index and predisposes to childhood and adult obesity. Science 316, 889-894.

27. Dina C, Meyre D \& Gallina S (2007) Variation in FTO contributes to childhood obesity and severe adult obesity. Nat Genet 39, 724-726.

28. Drapeau V, Provencher V, Lemieux S et al. (2003) Do 6-y changes in eating behaviors predict changes in body weight? Results from the Québec Family Study. Int J Obes Relat Metab Disord 27, 808-814.

29. Stice E, Presnell K, Shaw H et al. (2005) Psychological and behavioral risk factors for obesity onset in adolescent girls: a prospective study. J Consult Clin Psychol $\mathbf{7 3}$, 195-202.

30. McGuire MT, Wing RR, Klem ML et al. (1999) What predicts weight regain in a group of successful weight losers? J Consult Clin Psychol 67, 177-185.

31. Van Strien T, Frijters JE, Bergers GPA et al. (1986) Dutch eating behavior questionnaire for assessment of restrained, emotional and external eating behavior. Int J Eat Disord 5, 295-315.

32. Montoye HJ, Kemper HCG, Saris WHM et al. (1996) Measuring Physical Activity and Energy Expenditure. Champaign, IL: Human Kinetics. 